\title{
O USO DE JOGOS EDUCACIONAIS NA PRÁTICA DO ENSINO
}

\author{
The use of educational games in teaching practice \\ El uso de juegos educativos en la práctica docente
}

\author{
Jainara Vanessa A dos Santos ${ }^{1}$, Eduardo B. Oliveira ${ }^{1}$, Tiago César P. de Sousa ${ }^{1}$, \\ Érica Cupertino Gomes ${ }^{1}$, Jonierson A. da Cruz ${ }^{2}$. \\ ${ }^{1}$ Laboratório de Ensino de Física, Licenciatura em Física, Universidade Federal do Tocantins, Campus \\ Cimba, Brasil. \\ ${ }^{2}$ Instituto Federal do Tocantins, Campus Araguaína, Brasil.
}

*Correspondência: e-mail: jainaravanessaa@gmail.com.

Artigo recebido em 27/02/2020 aprovado em 09/04/2020 publicado em 20/04/2020.

\section{INTRODUÇÃO}

Diversas são as pesquisas que buscam estratégias para melhorar o ensino de Física nas escolas. No entanto, ainda existe uma grande lacuna entre as pesquisas e a realidade vivida em sala de aula. Sob essa perspectiva é importante utilizar metodologias diferentes, pois elas podem ajudar na aprendizagem dos alunos. Um exemplo é a utilização das abordagens lúdicas, principalmente os jogos educativos que, de acordo com Cardoso (1996), não pode ser visto como mais um procedimento que é capaz de promover a aquisição do conhecimento, mas deve apresentar-se como uma atividade capaz de provocar no estudante um desafio, permitindo uma maior participação na aula.

Com o objetivo de ensinar Física, os jogos podem ser bastante ricos. O principal propósito é despertar o interesse dos alunos e motivá-los a aprender mais sobre o conteúdo abordado no jogo. Segundo Puloski,

\begin{abstract}
“...quando a criança se interessa pelo que faz, é capaz de empreender esforços até o limite de sua resistência física. Apenas quando as crianças se empenham em sua própria aprendizagem, apenas então tomará forma à verdadeira disciplina - a disciplina que as próprias crianças desejam e aprovam (Puloski 1983).”
\end{abstract}

Ausubel (2003) acredita que o aluno precisa "querer" aprender e relacionar o novo conhecimento com o que ele já tem, tornando assim sua aprendizagem significativa. Ainda assim, a aprendizagem não depende apenas da vontade do aluno, mas também do modo como é apresentado o conteúdo, pois se não houver significado para o aluno haverá apenas um acúmulo do conteúdo, de maneira mecânica.

Diante disso, o presente trabalho tem por objetivo apresentar a utilização de um jogo didático para o ensino de Física realizado por acadêmicos residentes do Programa Residência Pedagógica com alunos da $2^{\circ}$ série do Instituto Federal do Tocantins campus Araguaína. 


\section{METODOLOGIAS E MATERIAIS}

O jogo escolhido, foi um jogo de tabuleiro confeccionado em um projeto de iniciação cientifica. A metodologia do jogo é a mesma de um tabuleiro simples, foi explicado para os alunos as regras do jogo e todos os detalhes possíveis, os alunos foram divididos em grupos para jogar.

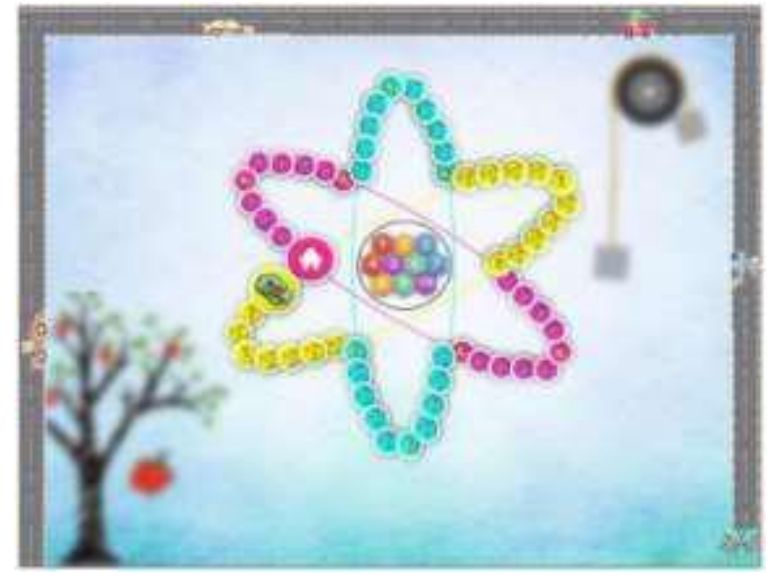

Figura 1. Tabuleiro do jogo

As perguntas do jogo foram voltadas para os conteúdos de Física nas seguintes áreas: termodinâmica; temperatura; calor e sua propagação; dilatação térmica dos sólidos e dos líquidos; ondas; reflexão da luz e fundamentos da óptica geométrica.

\section{RESULTADOS E DISCUSSÃO}

O uso do jogo na aula de Física foi utilizado como uma revisão de todo o conteúdo que os alunos estudaram durante o ano. Do ponto de vista dos residentes e do preceptor da escola campo, a aplicação do projeto foi bem-sucedida pois, a maioria dos alunos participaram, interagiram e se divertiram com a nova maneira de revisar o que aprenderam.

Foram feitas mais de 20 perguntas sobre os conteúdos que o professor, no decorrer do ano letivo, explicou. Destas, aproximadamente $80 \%$ foram respondidas corretamente.

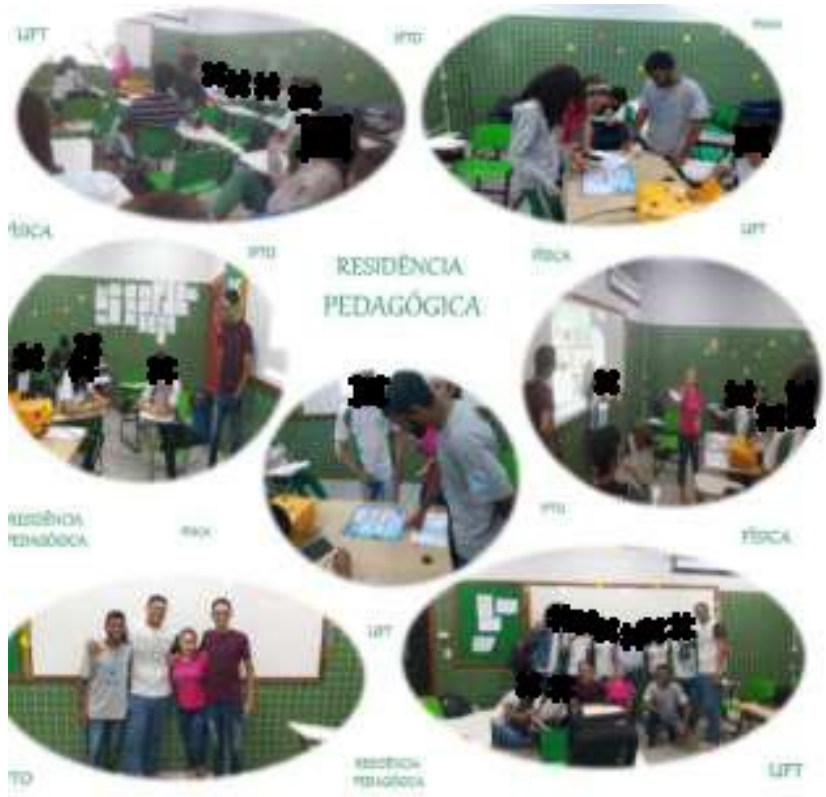

Figura 2. Projeto sendo aplicado em sala de aula.

Por fim, foram realizados três perguntas básicas para saber o impacto e o nível de satisfação dos mesmos. Os gráficos 1 e 2 demonstram os resultados obtidos:

Gráfico 1. Respostas dos alunos sobre a satisfação com o 140 uso da metodologia

Você gostou da aula utilizando o tabuleiro como instrumento de ensino?

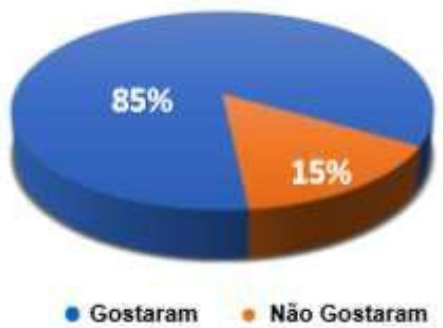

Gráfico 2. Respostas dos alunos sobre o impacto da metodologia

Gostaria que houvesse mais aulas assim com jogos e outros meios de ensino mais dinâmicos?

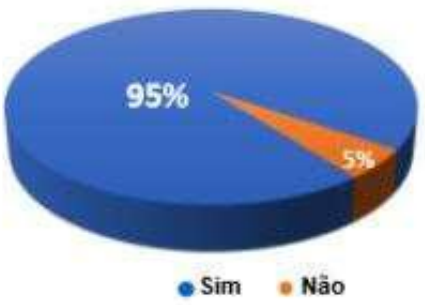


Resposta de um dos alunos à terceira pergunta:

3) O que vocễ achou da utilização de jogos educativos na sala de aula como método de ensino?

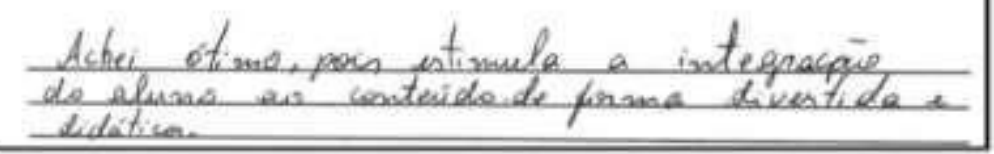

\section{CONCLUSÃO}

Pode-se observar que o método de ensino por meio de jogos didáticos é uma boa estratégia para o ensino de Física e das demais disciplinas curriculares, mas como em toda metodologia, ela vem com seus desafios.

O primeiro desafio encontrado foi a elaboração do tabuleiro, pois tinha que ser algo diferente e que chamasse a atenção dos adolescentes. Então foi optado a utilização de um tabuleiro feito em um projeto de iniciação cientifica - PIVIC/UFT.

O segundo foi a confecção das cartas, pois além de ser mais de 20 perguntas não poderiam ser difíceis e nem fáceis demais para não desanimar os alunos. Então foi decidido qual conteúdo cada residente ficaria e assim cada um fez 5 perguntas de seu conteúdo.

E o terceiro desafio encontrado foi durante a aplicação do jogo, pois ficou difícil manter a organização dos alunos e controle das conversas paralelas durante a aula.

Apesar dos desafios encontrados os alunos conseguiram interagir com os conteúdos considerados e fortaleceram os vínculos sociais da turma. Além disso, os residentes puderam perceber que este tipo diferente de abordagem desperta o interesse dos alunos tanto em aprender como em participar da aula.

Os gráficos e o comentário de um aluno demonstram a aprovação e o desejo deles de haver mais atividades diferentes na sala de aula. Os resultados obtidos foram satisfatórios, tanto para os alunos como para nós futuros professores.

\section{AGRADECIMENTO}

A DEUS, a CAPES, a UFT, ao IFTO, a Profa. Dra. Érica Cupertino Gomes, ao Prof. Dr. Matheus P. Lobo, ao Prof. Ms. Jonierson A. da Cruz e a todos os colegas da Residência Pedagógica - Física/UFT.

\section{REFERÊNCIAS}

AUSUBEL, D. Aquisição e retenção de conhecimentos: uma perspectiva cognitiva. Lisboa: editora plátano,2003.

CARDOSO, R. C. T. Jogar para aprender língua estrangeira na escola. Dissertação (mestrado em linguística aplicada) - universidade estadual de campinas, instituto de estudos da linguagem, são paulo. 1996.

PULOSKI, M.A.S. Compreendendo Piaget:uma introdução ao desenvolvimento cognitivo da criança. Rio de Janeiro: Zahar, 1983. 